
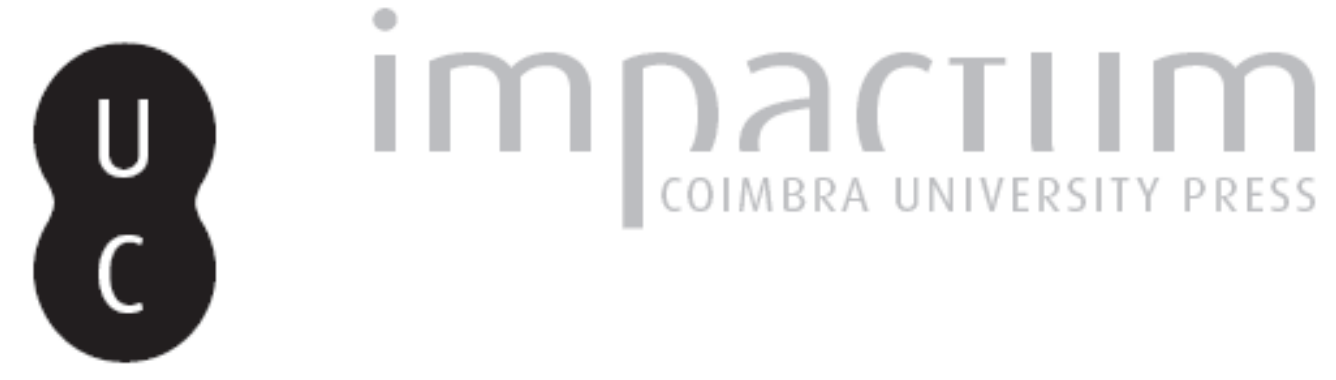

\title{
[Recensão a] O último Regimento e o Regimento da Economia da Inquisição de Goa. Leitura e Prefácio de Raúl Rego
}
Autor(es):
Torgal, Luís Reis

Publicado por: Imprensa da Universidade de Coimbra

URL persistente:

URI:http://hdl.handle.net/10316.2/43844

DOI:

DOI:https://doi.org/10.14195/2183-8925_6_16

Accessed : $\quad$ 26-Apr-2023 06:06:53

A navegação consulta e descarregamento dos títulos inseridos nas Bibliotecas Digitais UC Digitalis, UC Pombalina e UC Impactum, pressupõem a aceitação plena e sem reservas dos Termos e Condições de Uso destas Bibliotecas Digitais, disponíveis em https://digitalis.uc.pt/pt-pt/termos.

Conforme exposto nos referidos Termos e Condições de Uso, o descarregamento de títulos de acesso restrito requer uma licença válida de autorização devendo o utilizador aceder ao(s) documento(s) a partir de um endereço de IP da instituição detentora da supramencionada licença.

Ao utilizador é apenas permitido o descarregamento para uso pessoal, pelo que o emprego do(s) título(s) descarregado(s) para outro fim, designadamente comercial, carece de autorização do respetivo autor ou editor da obra.

Na medida em que todas as obras da UC Digitalis se encontram protegidas pelo Código do Direito de Autor e Direitos Conexos e demais legislação aplicável, toda a cópia, parcial ou total, deste documento, nos casos em que é legalmente admitida, deverá conter ou fazer-se acompanhar por este aviso.

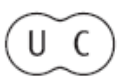




\section{REVISTA DE HISTORIA DAS IDEIAS 6}

\section{. \\ REVOLTAS E REVOLUCOEES}

*

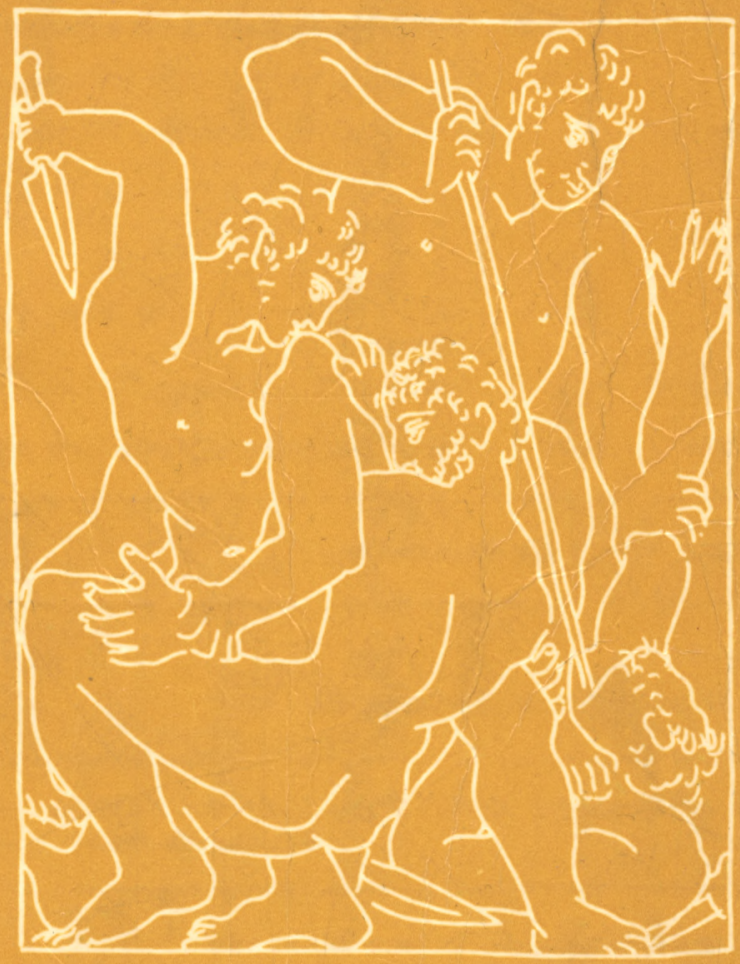

INSTITUTO DE HISTORIA E TEORIA DAS IDEIAS FACULDADE DE LETRAS 
o último Regimento e o Regimento da Economia da Inquisição de Goa. Leitura e Prefácio de Raúl Rego. Biblioteca Nacional. Série Documental. Lisboa, 1983. 155 pp.

No seguimento da publicação de outros documentos relativos à Inquisição - o processo de Damião de Góis e o Regimento pombalino de 1774 - Raúl Rego apresenta agora, nesta edição da Biblioteca Nacional de Lisboa, o Regimento mariano de Goa de 1778 e o seu "Regimento da Economia», este totalmente inédito e o outro de que apenas tinha sido dado a conhecer ao público uma pequena parte. São fontes bem significativas - conforme o salienta o prefaciador - da política de marcha-atrás levada a efeito, neste particular, pelo governo de D. Maria I. Nisso consiste o seu principal motivo de interesse. Extinta em Goa em 1773 (e reformada no Continente em 1774), a Inquisição é restaurada ali 5 anos depois. E, curiosamente, o Cardeal da Cunha, o Inquisidor ao serviço do regalismo de Pombal, que justificara a sua abolição no Oriente, vem agora fundamentar a sua restauração, em momento de orientação político-eclesiástica bem diferente. De resto, conforme revela Rego, este Regimento de Goa, embora seguindo em linhas gerais o Regimento de 1774, é esvaziado da ideologia galicanista que enformou a reforma inquisitorial pombalina.

A edição apresentada por Raúl Rego não é uma edição crítica. A sua leitura actualizou a grafia e o texto não é acompanhado de notas explicativas. Se, a meu ver, estas são necessárias para esclarecer o leitor, e não devem nunca faltar numa qualquer edição, já entendo que a actualização gráfica - que se torna cada vez mais vulgar, mesmo em edições eruditas - vem exactamente ao encontro do interesse do leitor comum, que teria mais dificuldade em ler estes documentos na sua forma original. Seja como for, Raúl Rego prestou mais uma vez um assinalável contributo ao dar a conhecer esta documentação.

Rego é, aliás, assumidamente, no campo da história, apenas um divulgador. Com a sua experiência de jornalista e com a sua vivência de político, tem sobretudo vocação para surpreender a "realidade que passa» e não para levar a efeito profundas análises estruturais. Assim, as suas reflexões históricas assumem a vivacidade de uma notícia e por vezes a acutilância crítica de um discurso político. Quando aborda o fenómeno inquisitorial vêm, pois, ao de cima os seus ideais, e até os seus traumas. Rego é um homem que se opõe à repressão, venha ela da ditadura do "Estado Novo» ou do tribunal do Santo Ofício. Não se pretenda, portanto, encontrar nas 
suas páginas uma análise imparcial. Em boa verdade, todavia, com a crítica ao positivismo historiográfico, pôs-se também em causa a imparcialidade científica da história. $\mathrm{E}$ desmistificou-se concretamente a imparcialidade de certas análises que, no caso pendente, procuravam compreender, se não mesmo justificar, a aç̧ão inquisitorial, explicando-a à luz dos conceitos do tempo. Ainda hoje é necessário pôr em causa essa alegada isenção científica, quando se lêem obras que deliberadamente omitem realidades menos dignas de situações políticas concretas. E o caso da obra de Franco Nogueira sobre o regime salazarista-marcelista (História de Portugal, edição de Barcelos, Suplemento II), que não dedica um só capítulo, nem sequer um só parágrafo, aos seus aparelhos repressivos. Se realmente não podemos cair nos vícios de uma história ideológica (ou, se quisermos, de uma ideologia historiográfica), não podemos pensar que a história se faz sem ideias. Tal facto, de resto, não colide com a objectividade que deve ser exigida à história e que resulta sobretudo da utilização de métodos actualizados, de conceitos operatórios constantemente repensados, de uma dimensionação totalizante da realidade. Em conclusão, ainda que no Raúl Rego comentador da fonte histórica possa transparecer a visão palpitante do jornalista e a crítica incisiva do homem político - note-se como salientou com particular acuidade que a fundação da Inquisição em Goa correspondia à forma mais dramática da colonização, isto é, a um fenómeno de enculturação, de imposição do catolicismo e da sua cultura a sociedades culturalmente formadas - não procura forçar o documento a justificar a sua ideologia.

Por outro lado, com as limitações de que ele próprio tem consciência, Rego é hoje um dos poucos estudiosos da Inquisição em Portugal. O exemplo de investigadores como António Baião e João Lúcio de Azevedo, que abriram perspectivas ao estudo do fenómeno inquisitorial, não deu ainda os seus frutos senão, por exemplo, nas importantes publicações documentais de Mário Brandão, nos ensaios pioneiros de uma interpretação global de António José Saraiva, nas notáveis análises histórico-culturais de Silva Dias, nas pesquisas ultimamente orientadas por Isaías da Rosa Pereira, ou nas investigações que estão sendo levadas a efeito por Veiga Torres. Isto para além de alguns trabalhos de relevo da autoria de estrangeiros, entre os quais teremos de destacar (por discutíveis e discutidos que sejam os seus escritos) o nome de Révah. Que esta publicação de Raúl Rego sirva de incentivo aos nossos historiadores, sobretudo aos de Lisboa, que têm a documentação inquisitorial ali mesmo à mão, na Torre do 
Tombo. Quanto a nós, divididos por outros interesses e por outras tarefas de investigação, tentaremos ao menos publicar o processo exemplar de Manuel Fernandes Vila Real, que há já bastante tempo vimos a prometer e cuja leitura, levada a efeito pelas bibliotecárias-arquivistas Ângela Gama e Ana Maria Osório, está em fase de grande adiantamento. Mas impõe-se sobretudo um trabalho sistemático, feito por equipas de investigadores. Tal como as tentativas que estão a ser feitas nesse sentido no Brasil, para o caso dos cristãos-novos, por uma equipa dirigida pela professora da Universidade de São Paulo, Anita Novinsky. Oxalá que um trabalho, projectado pelo Núcleo de Sociologia Histórica do Instituto Gulbenkian de Ciência e orientado por Robert Rowland, de tratamento informático de dados extraídos dos arquivos do Santo Ofício possa ser levado a bom termo, pois será um primeiro caminho para essa pesquisa sistemática.

Para finalizar estas reflexões tecidas à volta do livro publicado por Raúl Rego, uma palavra de louvor é devida à Biblioteca Nacional de Lisboa, que tem prosseguido na importante tarefa de dar à luz documentos inéditos ou de reeditar obras esquecidas ou dispersas. E essa iniciativa é de valorizar ainda porque uma instituição com o seu prestígio não se tem limitado à edição erudita e académica, consciente de que a divulgação séria faz parte importante das suas atribuições. As suas sugestivas e constantes exposições e mostras documentais e bibliográficas são também uma prova dessa vivacidade. Uma biblioteca não é um depósito de livros - é uma instituição de cultura viva e actuante.

Luís Reis Torgal

Enrique Martínez Ruiz, La Delincuencia Contemporanea. Introducción a la delincuencia isabelina, Universidad de Granada, 1982. 276+13 in. pp. (Prólogo de Vicente Palacio Atard).

De Espanha nos chegou o título que ilustra, segundo pensamos, a variedade e a importância da recente historiografia espanhola e a sua abertura (à semelhança das de outros países) às «novas» correntes, interpretações e temáticas no domínio da história.

$\mathrm{Na}$ esteira da "escola» dos Annales e de outros contributos, desde há décadas que se vêm afirmando novas concepções, arroteando novos terrenos e desenhando mais am- 